\title{
SCIENTIFIC RESEARCH AND ITS ORGANIZATION
}

$I^{N}$ $\mathrm{N}$ the course of the first Ludwig Prandtl Memorial Leeture, delivered before the German Scientific Society for Aeronautics (W.G.L.) at Göttingen on February 4, Prof. Albert Betz strongly urged certain changes in the approach to scientific research in the Western world. Prof. Betz, of the University of Göttingen, a distinguished aerodynamicist and probably the oldest active representative of the Göttingen school of physics, was the closest collaborator of the late Ludwig Prandtl. He spoke on "Fifty Years of Research in the Field of Fluid Dynamics", and his critical survey of past achievements culminated in two specific reproaches.

The first was directed against the mathematicians, who have taken too little interest in providing truly comprehensive theories in fluid dynamics. Such general treatment would save expensive ad hoc experimentation for purposes of aeronautical engineering. It seemed to him that the spirit of Felix Klein (founder of the famous school of theoretical physics at Göttingen) is no longer alive among mathematicians. Klein, himself a mathematician, had conceived of the mathematicians as acting as a sort of 'general staff' for the engineering sciences. But mathematicians to-day seem to shirk tackling problems from other domains, in particular those of applied physics. The second criticism of the development of fluid dynamics concerned the lack of really gifted physicists who could analyse a complicated question and solve the component problems in a way which, after re-constitution, would yield comprehensive solutions to the original problem.

In general, mass production and mechanization have been introduced into scientific research, with dire consequences for the quality of the output. Expensive laboratory equipment (which might often be replaced by much cheaper and simpler devices) and numerous staff, with automation and electronic processing of the results, have helped relatively little to stimulate genuine advance, except in detail and over ad hoc problems.

The size and variety of experimental equipment, for example, the gigantic modern wind-tunnels, have called for mass-production of scientists to handle it. Since only a small percentage is really sufficiently gifted to achieve progress in research, a 'scientific proletariat' has thus been created. This has cluttered up the pages of periodicals and filled the days of congresses with mediocre contributions. It has also affected the quality of the teaching and depressed the standards of colleges and universities. Worst of all, nembers of this scientific proletariat have managed to find their way to the handling of problems for which they are unsuited. In this way, gifted research workers are kept out, or have shirked the responsibility. Training of the mass of scientists has often been reduced to mere cramming for examinations. It should not be forgotten that the level of intelligence is decreasing in the Western world. Under the influence of press, radio, cinema and television, the ability to think independently and along scientific lines has become rare. It is just that faculty which the research scientist needs most.
Gifted scientists are too little attracted by research, and frequently too much impressed by large institutes and elaborate facilities for experimenting. In the majority of instances, progress in basic research needs a few carefully chosen experiments with rather simple devices. Size and complication of the laboratory equipment are often a disadvantage. Even more important are the conditions under which a scientist has to work. Research cannot be conducted effectively when the scientist is expected to produce results to order ; he should be left free to investigate those problems to which he is most attracted. Betz recalled the habit of Prandtl 'playing', by repeating an experiment time after time with minute variations. It was, of course, an essential part of his research to study the phenomena closely and to cerrelate them with each other, before drawing conclusions. Under pressure of work and hustling, such fruitful research could not be done.

Gifted research workers should not be directed into the administration of large research institutes. There was the apt advice on how to prevent a scientific rival from forging ahead: this was to get for him a large institute, the administration of which would rapidly put an end to his research productivity. Research workers might advise in the direction of scientific output, but they should not head such institutions.

It is most important to free research scientists from oppression by bureaucracy. Bureaucracy has encroached more and more on the domains of science. This interference with the conduct of research presents a grave danger, and the process should be reversed as soon as possible. The progress of science should not be interfered with by the instantaneous needs of industry or by the requirements of the Services. The scientist should be left free to spend his means for research in the way that he judges best.

The U.S.S.R. has now become a formidable rival in the field of scientific progress. Research was sponsored, equipped and conducted on an exemplary scale. The training facilities left little to be desired. The system of regimentation is totally unacceptable to Western civilization, and Prof. Betz thought that, in the end, the free research scientist would forge ahead of anyone who worked under compulsion and direction. But the attitude towards research in the West requires re-orientation: the scientist's needs deserve more consideration. It should not be forgotten that nowadays not the quantity of weapons but the quality of the scientists mattered most.

Concluding, Prof. Betz recalled W. v. Harnack's dedication when handing over to L. Prandtl the new Institute for Fluid Dynamics in 1925, on behalf of the Kaiser-Wilhelm Society for the Promotion of Science: "Our task is to select the research scientist, and we do so with the utmost care. If we have found him, we provide him with as much money and all the means necessary to conduct his research. This is the end of our task. It is left to the scientist to spend the money and to apply the means as he judges best. We do not interfere". After all these years of the Göttingen Institute, Prof. Betz commented, it has become obvious how sensible this approach to research has been.

A. R. WEYL 